Check for updates

Cite this: J. Mater. Chem. A, 2021, 9, 10477

Received 24th February 2021 Accepted 7th April 2021

DOI: $10.1039 / d 1 t a 01639 c$

rsc.li/materials-a

\section{Stoichiometrically driven disorder and local diffusion in NMC cathodes $\uparrow$}

\author{
Thomas E. Ashton, (ID)*a Peter J. Baker, (ID) ${ }^{\mathrm{b}}$ Carlos Sotelo-Vazquez, (D) a
}

Charles J. M. Footer, ${ }^{a}$ Kenji. M. Kojima, ${ }^{c d}$ Takeshi Matsukawa, (D) ${ }^{\text {e }}$ Takashi Kamiyama $^{f}$ and Jawwad A. Darr ${ }^{a}$

\begin{abstract}
Major structural differences in lithium nickel manganese cobalt oxides (NMC) prepared under identical conditions have been uncovered using neutron powder diffraction. Sample NMC-622 was obtained as a single $R \overline{3} m$ crystal structure with little defects, whereas NMC-811 showed significant Li deficiency and NMC-433 formed three distinct phases; ordered $R \overline{3} m$, disordered $R \overline{3} m$ and a $C 2 / m$ phase. Local diffusion behaviour was also studied by muon spin relaxation ( $\mu \mathrm{SR})$. It was observed that single phase $R \overline{3} \mathrm{~m}$ NMC-622 showed a higher lithium diffusion coefficient $\left(4.4 \times 10^{-11} \mathrm{~cm}^{2} \mathrm{~s}^{-1}\right)$ compared to lithium deficient NMC-811 $\left(2.9 \times 10^{-11} \mathrm{~cm}^{2} \mathrm{~s}^{-1}\right)$, or the highly disordered NMC-433 $\left(3.4 \times 10^{-11} \mathrm{~cm}^{2} \mathrm{~s}^{-1}\right)$. Furthermore, activation energies for the Li diffusion process were estimated to be $58 \mathrm{meV}, 61 \mathrm{meV}$ and 28 meV for NMC-811, NMC-622 and NMC-433, respectively.
\end{abstract}

\section{Introduction}

In response to the ever growing environmental and societal demands for decarbonised electrification, much effort has been afforded to the development of lithium-ion batteries (LIBs). Despite LIBs offering a reliable and efficient method of storing energy for portable electronics, transport and grid-based energy, the underpinning materials chemistry employed in such devices continue to be of paramount importance. Lithiated nickel manganese cobalt oxide (NMC) cathodes currently remain one of the most promising cathode materials families for commercial LIBs. ${ }^{1,2}$ The attraction of NMC cathodes lies in their demonstrated stability over several thousand cycles and the promise of high energy densities. ${ }^{3}$ Furthermore, the electrochemical attributes of these cathodes can be tuned by altering the metal ratios of $\mathrm{Ni}, \mathrm{Mn}$, and $\mathrm{Co}$. Recent attention has been focused on high-nickel NMC cathodes ( $>80 \%$ of the metals being $\mathrm{Ni})$ due to their increased capacity $\left(\sim 200 \mathrm{~mA} \mathrm{~h} \mathrm{~g}^{-1}\right)$ versus lower Ni concentration NMCs. ${ }^{4}$ This increase in Ni also allows higher maximum voltages to be accessed (approaching $5 \mathrm{~V}$

${ }^{a}$ University College London, Department of Chemistry, Bloomsbury, London, UK. E-mail: t.ashton@ucl.ac.uk

${ }^{b}$ Rutherford Appleton Laboratory, ISIS, Didcot, Oxfordshire, UK

'TRIUMF, Centre for Molecular and Materials Science, Vancouver, BC, Canada

${ }^{d}$ University of British Columbia, Stewart Blusson Quantum Matter Institute, Vancouver, BC, Canada

'Ibaraki University, Frontier Research Center for Applied Atomic Sciences, Mito, Ibaraki, Japan

${ }^{f}$ High Energy Accelerator Research Organisation (KEK), Tsukuba, Ibaraki, Japan

$\dagger$ Electronic supplementary information (ESI) available. See DOI: $10.1039 / \mathrm{d} 1 \mathrm{ta} 01639 \mathrm{c}$ versus $\mathrm{Li} / \mathrm{Li}^{+}$) during electrochemical cycling, increasing energy density. ${ }^{5}$ However, increasing the Ni concentration may also lead to increased structural instability, both during synthesis and electrochemical cycling. ${ }^{6}$ Thus, significant challenges still remain.

The electrochemically attractive crystal phase of NMC adopts a layered $R \overline{3} m$ structure, typical of $\mathrm{LiCoO}_{2}$. Alternating slabs of $\mathrm{Li}$ atoms on the $3 \mathrm{a}$ sites are sandwiched between layers of $\mathrm{MO}_{6}$ octahedra $(\mathrm{M}=\mathrm{Ni}, \mathrm{Mn}$ or $\mathrm{Co})$, where $\mathrm{M}$ are located on the $3 \mathrm{~b}$ sites (Fig. 1). ${ }^{7}$ Isolation of a defect-free $R \overline{3} m$ phase has proven to be a sensitive process due to thermodynamic limitations on structural evolution during heating. ${ }^{8-10}$ Typically, syntheses are carried out in a two-step reaction. The first reaction

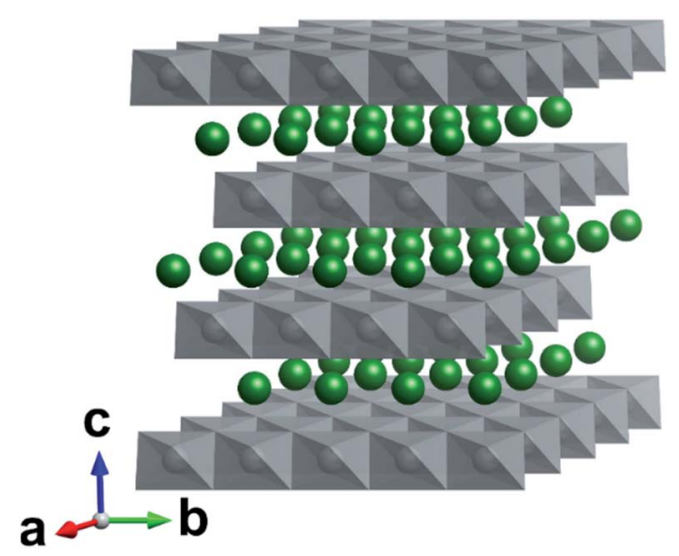

Fig. 1 Crystal structure of $R \overline{3} m \mathrm{LiMO}_{2}(\mathrm{M}=\mathrm{Ni}, \mathrm{Mn}, \mathrm{Co})$. Li atoms are shown in green and $\mathrm{MO}_{6}$ polyhedra in grey. In the perfect structure, $\mathrm{Li}$ diffusion occurs in the ab plane. 
consolidates the constituent transition metals ( $\mathrm{Ni}, \mathrm{Mn}$ and $\mathrm{Co}$ ) into a single precursor, usually by coprecipitation at temperatures $<350^{\circ} \mathrm{C}^{11,12}$ The second step requires a solid-state reaction between a lithium source (such as $\mathrm{LiOH}$ or $\mathrm{Li}_{2} \mathrm{CO}_{3}$ ) and the aforementioned precursors, typically in a furnace at $>800{ }^{\circ} \mathrm{C}$ for 5 to $48 \mathrm{~h} .^{11}$ Due to these high temperatures and long times, a fine interplay between lithium incorporation into the metal oxide and evaporative lithium loss arises. ${ }^{13}$ Thus, an excess of the Li source is commonly used, but consequently risks the formation of additional 'lithium-rich' phases. ${ }^{14}$ In combination, these reports also suggest that lithium incorporation becomes increasingly more difficult with greater $\mathrm{Ni}$ concentration, requiring longer times or higher synthesis temperatures.

Suppression of lithium-nickel cation mixing $\left(\mathrm{Li}_{3 \mathrm{a}}{ }^{+} / \mathrm{Ni}_{3 \mathrm{~b}}{ }^{2+}\right)$ has also been highlighted as a major synthetic challenge. ${ }^{15}$ Reportedly, this exchange can lead to further structural instability and lower intrinsic Li mobility (at elevated concentrations). $\mathrm{Li}_{3 \mathrm{a}}{ }^{+} / \mathrm{Ni}_{3 \mathrm{~b}}{ }^{2+}$ mixing is purportedly more probable in highnickel NMC due to the larger availability of $\mathrm{Ni}$, and thus a smaller amount of $R \overline{3} m$ templating $\mathrm{Co}^{3+}$, and $R \overline{3} m$ stabilising $\mathrm{Mn}^{4+} . \mathrm{Li}_{3 \mathrm{a}}{ }^{+} / \mathrm{Ni}_{3 \mathrm{~b}}{ }^{2+}$ mixing in NMC has commonly been assessed using the peak intensity ratios of the $I_{(003)}$ and $I_{(104)}$ by X-ray diffraction, however this analysis is limited and presumes the only contribution to these intensities is $\mathrm{Li}_{3 \mathrm{a}}{ }^{+} / \mathrm{Ni}_{3 \mathrm{~b}}{ }^{2+}$. Other contributions may include bifurcation of element rich and poor phases, Li deficiency, or the presence of impurity phases whose peaks overlap such as Li rich $C 2 / m$. Suggestions have also been made that the exchange of $\mathrm{Li}^{+}$and $\mathrm{Ni}^{2+}$ are not necessarily equivalent. ${ }^{16}$ Furthermore, the diminished X-ray attenuation of Li versus other elements (due to its lower relative mass) reduces the accuracy of such measurements. ${ }^{17}$ Therefore, advanced techniques such as Neutron Powder Diffraction (NPD) are key for gaining a more thorough understanding of structural chemistry.
Typically, Li ions migrate through the 2D Li plane and are reversibly removed and inserted from the crystals' surface. As the diffusion of lithium ultimately dictates the operation of intercalation cathodes such as NMC, these systems have been widely studied by a range of methods including cyclic voltammetry (CV) electrochemical impedance spectroscopy (EIS), galvanostatic intermittent titration technique (GITT) and solidstate lithium nuclear magnetic resonance (Li-NMR). ${ }^{18-21}$ Among these, muon spin relaxation $(\mu \mathrm{SR})$ remains a unique and powerful tool to probe the diffusive properties of lithium ions (among others) on a local scale. ${ }^{22}$ In contrast to bulk electrochemical methods, $\mu \mathrm{SR}$ is not limited by grain boundaries or electrode preparation. Thus, $\mu$ SR can establish diffusion coefficients $(D)$ and activation energies $\left(E_{\mathrm{a}}\right)$ specific to the crystal structures present, irrespective of the particle- or mesostructure. $\mu \mathrm{SR}$ has previously been employed on isostructural materials such as the parent $\mathrm{LiCoO}_{2}$ and sister $\mathrm{Li}_{n} \mathrm{Ni}_{x} \mathrm{Co}_{y} \mathrm{Al}_{z} \mathrm{O}_{2}$ materials, and have been in good agreement with computational predictions of $D_{\mathrm{Li}}$ and $E_{\mathrm{a}}$ values. ${ }^{23-26}$

Although many studies have been performed to characterise electrochemical performance, there is still a lack of understanding of the effect of increasing nickel concentration on the structure and its relationship with local lithium diffusion in NMC cathodes. Herein, we present the need for improved structural scrutiny and an evaluation of increasing $\mathrm{Ni}$ content on local structure by NPD and local diffusion by $\mu \mathrm{SR}$.

\section{Results and discussion}

\section{Structural and elemental characterisation}

NMC-433, NMC-622 and NMC-811 were all collected as fine black powders after solid state lithiation and analysed by inductively coupled plasma mass spectrometry (ICP-MS) to elucidate the bulk elemental composition (Fig. 2a). It was found
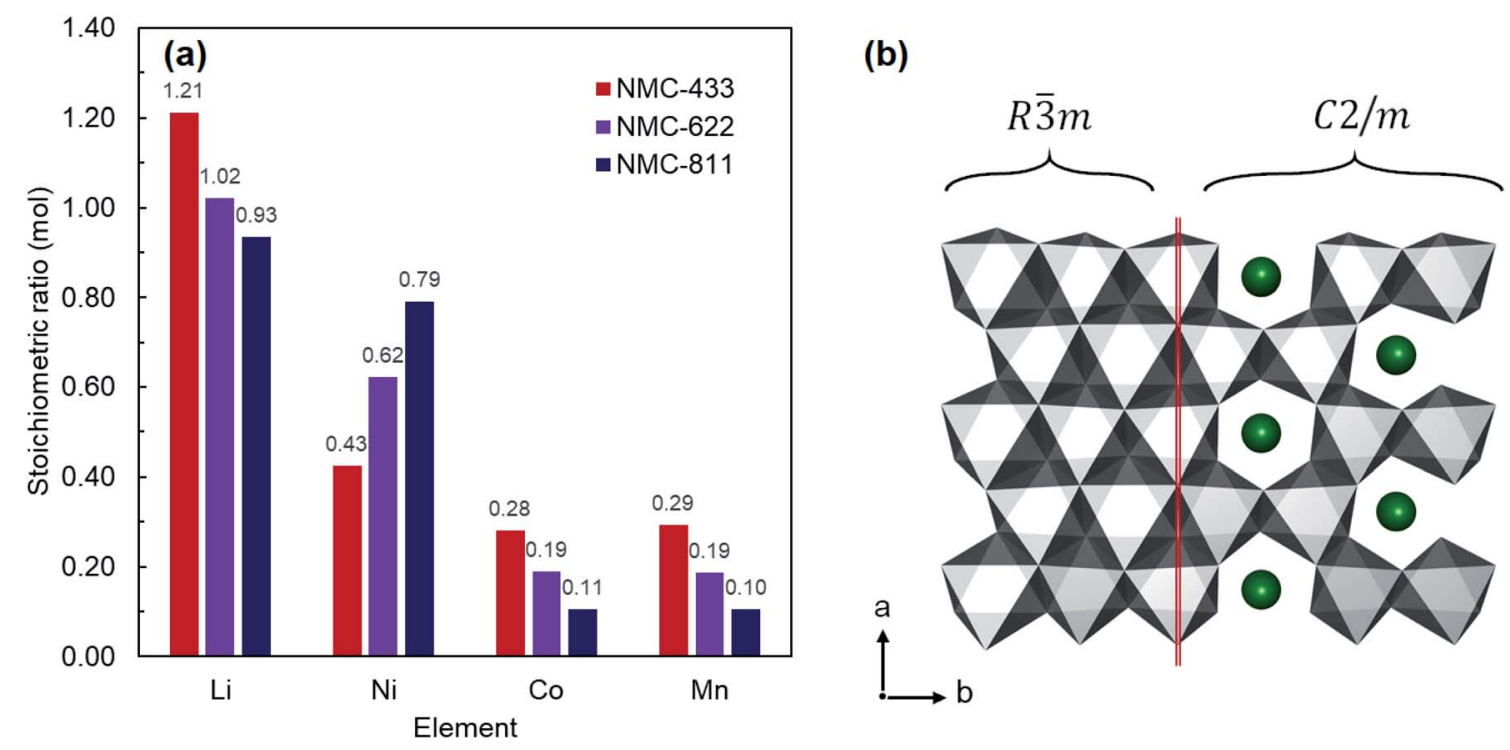

Fig. 2 (a) Elemental composition of the three NMC samples observed using inductively coupled plasma mass spectrometry. (b) Structural comparison of $R \overline{3} \mathrm{~m}$ and $\mathrm{C} 2 / \mathrm{m}$ structured NMC showing the replacement of metal ions (grey polyhedra) with $\mathrm{Li}^{+}$(green atoms) in the $\mathrm{MO}_{6}$ slab to generate a "honeycomb" structure. 


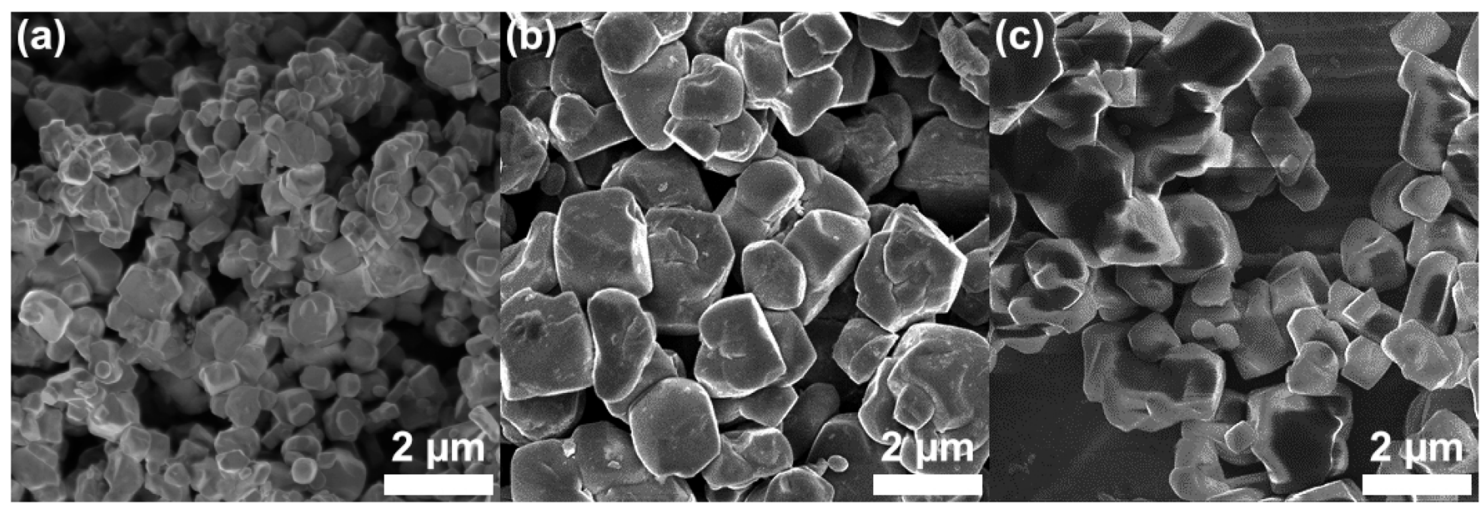

Fig. 3 Scanning electron micrographs of the three NMC samples prepared by a continuous hydrothermal approach followed by solid state lithiation (a) NMC-433, (b) NMC-622 and (c) NMC-811.

that the observed metals compositions were consistent with the nominal ratios; $\mathrm{Li}_{1.21} \mathrm{Ni}_{0.43} \mathrm{Mn}_{0.28} \mathrm{Co}_{0.29} \mathrm{O}_{2}$ (NMC-433), $\mathrm{Li}_{1.02}{ }^{-}$ $\mathrm{Ni}_{0.62} \mathrm{Co}_{0.19} \mathrm{Mn}_{0.19} \mathrm{O}_{2}$ (NMC-622) and $\mathrm{LiNi}_{0.93} \mathrm{Mn}_{0.11} \mathrm{Co}_{0.10} \mathrm{O}_{2}$ (NMC-811). Interestingly, the concentration of $\mathrm{Li}$ in each sample increased with decreasing $\mathrm{Ni}$ content, and a superstoichiometric quantity of lithium was identified in NMC-433. Ordering of $\mathrm{Li}$ into a hexagonal arrangement to give concentrations exceeding unity has previously been reported as a 'lithium-rich' phase, adopting a monoclinic $C 2 / m$ unit cell similar to $\mathrm{Li}_{2} \mathrm{MnO}_{3} \cdot{ }^{27-29}$ It is therefore suggested that it is the inclusion of increasing amounts of $\mathrm{Mn}$, rather than decreasing $\mathrm{Ni}$, would promote the higher concentration of Li observed in the samples as this phase is often observed in Mn rich NMC. ${ }^{30,31}$ A representation of the $\mathrm{MO}_{6}$ slab for both $R \overline{3} m$ and $C 2 / m$ is shown in Fig. $2 \mathrm{~b}$ where $\mathrm{MO}_{6}$ polyhedra are shown in grey and $\mathrm{Li}^{+}$in green. It can be seen that the only significant difference between the two structures is the replacement of $20 \%$ of the $\mathrm{M}$ sites are occupied by $\mathrm{Li}^{+}$to produce a 'honeycomb' structure.

Scanning electron microscopy (SEM) was used to further investigate particle size and morphology of the NMC samples. SEM of NMC-433, NMC-622 and NMC-811 (Fig. 3a-c, respectively) showed similar granular morphologies with typical diameters $\approx 2 \mu \mathrm{m}$. It is interesting to note that NMC-433 was significantly smaller than the other two materials. This may be due to the increased levels of Mn and/or Co providing resistance to particle sintering (as the same solid state lithiation conditions were used).

To corroborate the presence of a $C 2 / m$ phase, powder X-ray diffraction (PXRD) and subsequent Rietveld refinement was employed to evaluate the structure of the NMC samples (Fig. 4). All samples showed well defined, sharp peaks indicating a high degree of crystallinity and a rhombohedral $R \overline{3} m$ space group typical of $\mathrm{LiCoO}_{2}$ layered compounds (no contribution from a $C 2 / m$ phase was identified). However, previous reports have suggested that an increase in cobalt content (relative to the other metals present) can decrease the size of the $C 2 / m$ domains, causing them to be essentially amorphous to PXRD. ${ }^{32}$

The peak intensity ratio of the $I_{(003)} / I_{(104)}$ reflections has previously been used to evaluate $\mathrm{Li}_{3 \mathrm{a}}{ }^{+} / \mathrm{Ni}_{3 \mathrm{~b}}{ }^{2+}$ mixing within layered $R \overline{3} m$ metal oxides, where a value $<1.2$ suggests $\mathrm{Ni}^{2+}$ is purportedly present at the $\mathrm{Li}^{+} 3 \mathrm{~b}$ crystallographic site and vice versa. ${ }^{3,34}$ For the three materials, the values of $I_{(003)} / I_{(104)}$ suggested little or no cation mixing had occurred $(\mathrm{NMC}-433=1.2$, NMC-622 = 1.3 and NMC-811 = 1.2). To establish the contribution from cation mixing of $\mathrm{Li}^{+}$and $\mathrm{Ni}^{2+}$ on the $3 \mathrm{a}$ and $3 \mathrm{~b}$ sites, a $\left(\mathrm{Li}_{1-\delta} \mathrm{Ni}_{\delta}\right)_{3 \mathrm{~b}}\left(\mathrm{Li}_{\gamma} \mathrm{Ni}_{x-\gamma} \mathrm{Mn}_{y} \mathrm{Co}_{z}\right)_{3 \mathrm{a}} \mathrm{O}_{2}$ model was first applied during refinement. However, the model could not converge with real values of $\delta$ and $\gamma$, agreeing with the values of $I_{(003)} / I_{(104)}$ that no detectable cation mixing had occurred. While this is promising, Li occupancies are unlikely to be truly reliable due to the limited ability of low $Z$ elements (such as Li) to diffract X-rays.

\section{Neutron powder diffraction (NPD)}

To elucidate the crystal structure of the NMC materials further, neutron powder diffraction (NPD) was employed. Fig. 5 shows

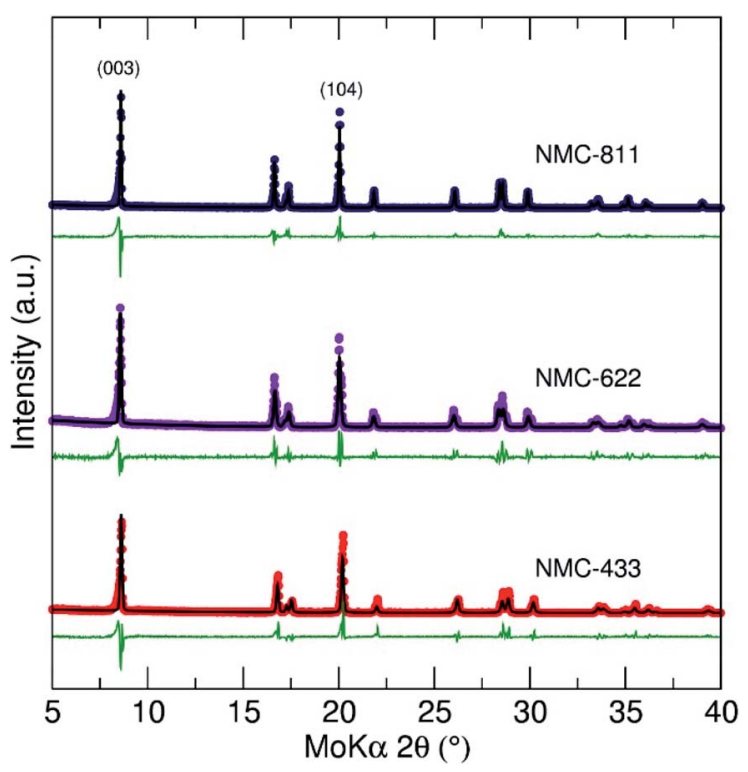

Fig. 4 Rietveld refinement of PXRD data collected for NMC-811, NMC-622 and NMC-433 prepared by a CHFS assisted route. All three patterns showed good agreement with the $R \overline{3} \mathrm{~m}$ reference patterns for their respective nominal stoichiometries. 


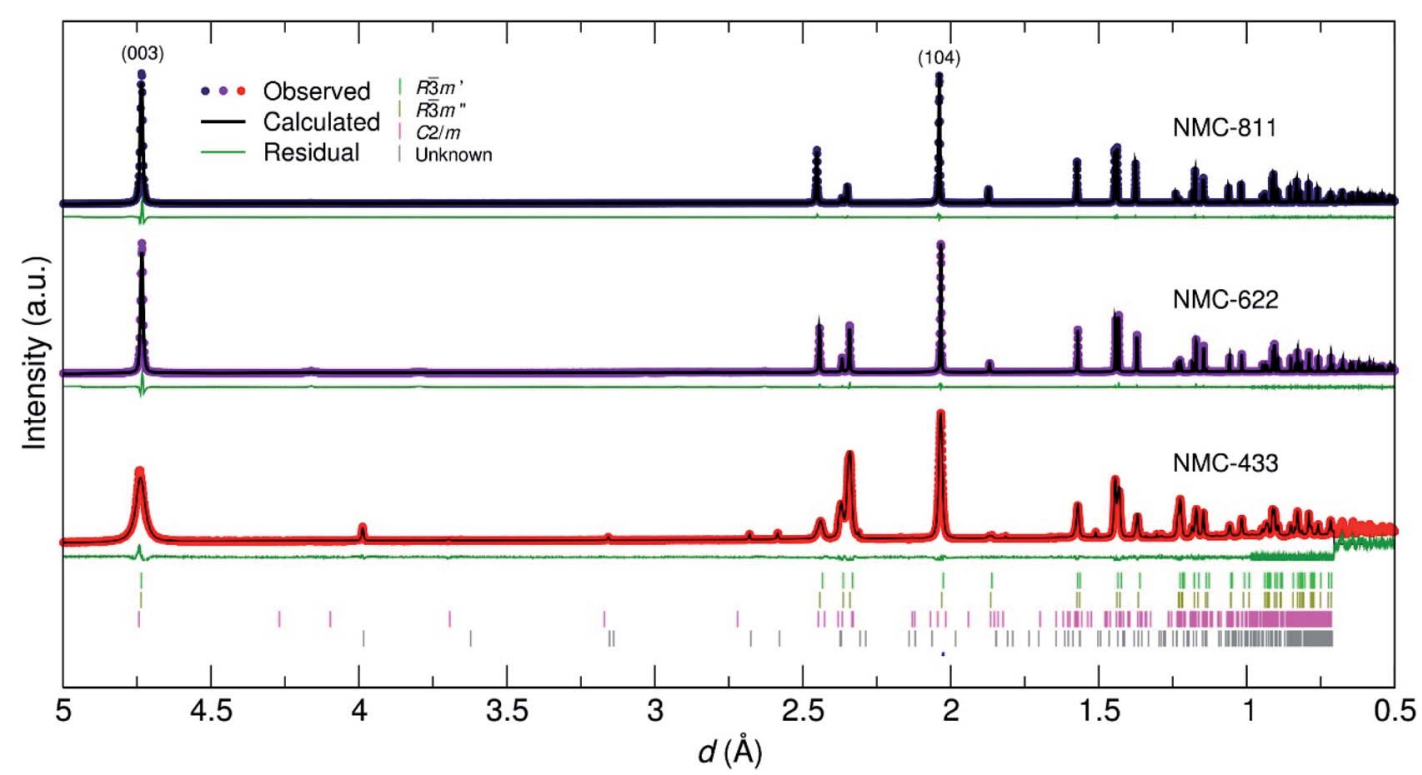

Fig. 5 Rietveld refinement of NPD data collected for NMC-811, NMC-622 and NMC-433 prepared by a CHFS assisted route. Relevant tick marks for NMC-433 have been included, where $R \overline{3} \mathrm{~m}^{\prime}$ and $R 3 \mathrm{~m}^{\prime \prime}$ denote the ordered and disordered NMC 433-phases, respectively.

the data collected for the three samples with respect to their $d$ spacing, and Rietveld refinement thereof. A full account of the fitting parameters can be found in the ESI. $\dagger$ While NMC-811 and NMC-622 were adequately fit with a single $R \overline{3} \mathrm{~m}$ phase (similar to the PXRD refinements), a small inclusion of $\mathrm{Li}_{2} \mathrm{O}$ (0.5 mol\%) and LiOH (4.9 mol\%) was identified in NMC-622 and an unknown impurity $(0.3 \mathrm{~mol} \%)$ in NMC-433 denoted by an asterisk. These observations led to a more correct stoichiometry being defined for NMC-622 $\left(\mathrm{Li}_{0.96} \mathrm{Ni}_{0.62} \mathrm{Co}_{0.19} \mathrm{Mn}_{0.19} \mathrm{O}_{2}\right)$. Similar to the PXRD refinements, a $\left(\mathrm{Li}_{1-\delta} \mathrm{Ni}_{\delta}\right)_{3 \mathrm{~b}}\left(\mathrm{Li}_{\gamma} \mathrm{Ni}_{x-\gamma} \mathrm{Mn}_{y} \mathrm{Co}_{z}\right)_{3 \mathrm{a}} \mathrm{O}_{2}$ model was employed with the determined values given in Table 1.

The values in Table 1 show that increasing [Ni] from 0.6 to 0.8 did not lead to a significant change in the absolute presence of $\mathrm{Ni}^{2+}{ }_{3 \mathrm{~b}}(\mathrm{NMC}-811=3.1 \%$, NMC-622 $=3.6 \%)$. However, these values do become significant when comparing them to the relative total Ni content of the material; $3.97 \%$ of the Ni in NMC811 is located on the 3a site in contrast to $9.42 \%$ of the $\mathrm{Ni}$ in NMC-622. Uniquely, although NMC-811 exhibits a low concentration of $\mathrm{Ni}_{3 \mathrm{~b}}{ }^{2+}$ mixing, it is not accompanied by an equivalent exchange of $\mathrm{Li}_{3 \mathrm{a}}{ }^{+}$due to a significant concentration $(\approx 7 \%)$ of vacancies on the $3 \mathrm{~b}$ site. This is an important observation that is only made possible through the use of NPD, as Li vacancies have a relatively small impact on the $I_{(003)} / I_{(104)}$ peak intensity ratio due to their low $Z$. A representation of this effect can be seen in Fig. 6, where values of $I_{(003)} / I_{(104)}$ from simulated PXRD patterns are given versus the concentration of mixing (Fig. 6a) and vacancy defects (Fig. 6b). In both cases, the location of Li makes the smallest contribution to the magnitude of $I_{(003)} / I_{(104)}$ with the smallest contribution attributed to Li vacancies. Thus, $\mathrm{Li}$ vacancies may be more easily concealed in PXRD than any other defect and supporting techniques, such as NPD or elemental analysis, are crucial.

In comparison, the structural refinement of NMC-433 was unable to converge with a single $R \overline{3} m$ phase. NMC- 433 was best fit by a combination of three phases: (i) a conventional, ordered $R \overline{3} m$ NMC (58.8 mol\%); (ii) a disordered $R \overline{3} m$ NMC phase (33.4 mol\%) and; (iii) a $C 2 / m \mathrm{Li}_{2} \mathrm{MnO}_{3}$ phase $(7.8 \mathrm{~mol} \%$ ). As shown in Fig. 2, the $C 2 / \mathrm{m}$ phase can be thought of as a highly disordered $R \overline{3} m$ with $20 \mathrm{~mol} \%$ of $\mathrm{Li}$ on the metal $3 \mathrm{~b}$ site. Thus, the $C 2 / m$ phase is "lithium rich" compared to the $R \overline{3} m$ phase, which agrees well with the overabundance of $\mathrm{Li}$ in NMC-433

Table 1 Occupancy values for the Rietveld refinement of neutron powder diffraction data collected for NMC-811 and NMC-622 based on a $\left(\mathrm{Li}_{1-\delta} \mathrm{Ni}_{\delta}\right)_{3 b}\left(\mathrm{Li}_{\gamma} \mathrm{Ni}_{x-\gamma} \mathrm{Mn}_{y} \mathrm{CO}_{z}\right)_{3 a} \mathrm{O}_{2}$ model for an $R \overline{3} m$ structure

\begin{tabular}{llllll}
\hline Atom & Site & NMC-811 & NMC-622 & NMC-433 (ordered) & NMC-433 (disordered) \\
\hline Li1 & 3b & $0.8982(2)$ & $0.9643(2)$ & $0.9579(9)$ & $0.876(2)$ \\
Ni2 & 3b & $0.0317(2)$ & $0.0356(2)$ & $0.0420(9)$ & $0.123(2)$ \\
Co1 & 3a & 0.11 & 0.19 & 0.25339 & 0.25339 \\
Ni1 & 3a & $0.7659(1)$ & $0.5877(1)$ & $0.433(1)$ & $0.255(3)$ \\
Li2 & 3a & $0.0240(1)$ & $0.0322(1)$ & $0.050(1)$ & $0.229(2)$ \\
Mn1 & 3a & 0.1 & 0.19 & 0.26244 & 0.26244 \\
O1 & 6c & 1 & 1 & - & 1 \\
Li $_{\text {vac. }}$ & 3b & 0.0701 & - & & -
\end{tabular}



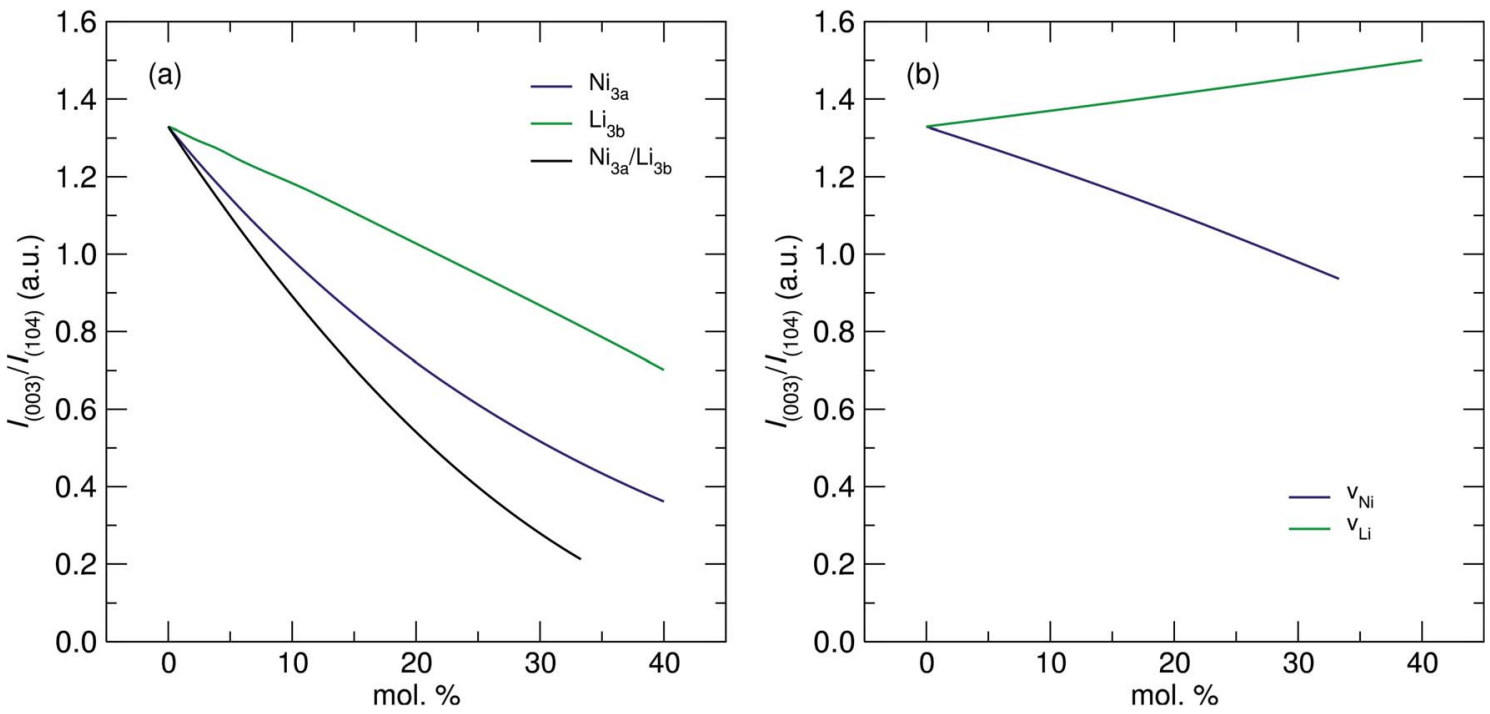

Fig. 6 Values of peak intensity ratios for $I_{(003)} / I_{(104)}$ for simulated diffraction patterns of NMC-811. (a) The effect of Li on an Ni site ( $\left.\mathrm{Li} i_{3 \mathrm{~b}}\right)$, Ni on an $\mathrm{Li}$ site $\left(\mathrm{Ni}_{3 \mathrm{a}}\right)$ and an exchange of $\mathrm{Li}$ and $\mathrm{Ni}$ both ways $\left(\mathrm{Ni}_{3 a} / \mathrm{Li}_{3 \mathrm{~b}}\right)$ on the $I_{(003)} / I_{(104)}$ peak intensity ratio. (b) The effect of vacancies of $\mathrm{Ni}$ and $\mathrm{Li}$ on the $I_{(003)} / I_{(104)}$ peak intensity ratio.

observed from ICP-MS analysis. Interestingly, the $\mathrm{C} 2 / \mathrm{m}$ containing NMC-433 exhibited broader peaks, suggesting a lower degree of crystallinity compared to the other two samples. This observation potentially supports the lack of PXRD evidence for a $C 2 / m$ phase by agreeing with prevailing suggestions that small domains of $C 2 / m$ disrupt the $R \overline{3} m$ crystals when Co is present in elevated concentrations in NMC materials.

A representation of the crystal structures for each of the major phases in NMC-811, NMC-622 and NMC-433 can be seen in Fig. 7 (derived from the respective NPD crystallographic refinements). From this figure three primary observations can be made: (i) although $\mathrm{Li}_{3 \mathrm{a}}{ }^{+} / \mathrm{Ni}_{3 \mathrm{~b}}{ }^{2+}$ mixing is present in low concentrations at the highest [Ni] content (NMC-811), $\mathrm{Li}^{+}$ vacancies are significantly prevalent; (ii) reducing [Ni] to 0.6 (as in NMC-622) eradicates the $\mathrm{Li}^{+}$vacancies while a low concentration of $\mathrm{Li}_{3 \mathrm{a}}{ }^{+} / \mathrm{Ni}_{3 \mathrm{~b}}{ }^{2+}$ mixing is maintained; (iii) further reducing [Ni] to 0.4 (NMC-433) leads to an overabundance of $\mathrm{Li}$, and the formation of multiple crystalline phases.

Regarding the final point; it is likely that the formation of multiple phases is due to the elevated presence of $\mathrm{Mn}$, rather than the lack of $\mathrm{Ni}$. Although $\mathrm{Li}_{3 \mathrm{a}}{ }^{+} / \mathrm{Ni}_{3 \mathrm{~b}}{ }^{2+}$ cation mixing is possible due to the magnetic structure of $\mathrm{Ni}$ (leading to a disordered $R \overline{3} \mathrm{~m}$ ), this is found to be more prominent at increasing $[\mathrm{Ni}]{ }^{35}$ Previous reports on similar oxides containing only $\mathrm{Mn}$ and Co have also shown phase separation of $C 2 / m$ and $R \overline{3} m$ in the absence of $\mathrm{Ni}^{36}{ }^{36} \mathrm{The}$ increase in [Co] can also be ruled out for (a) NMC-811

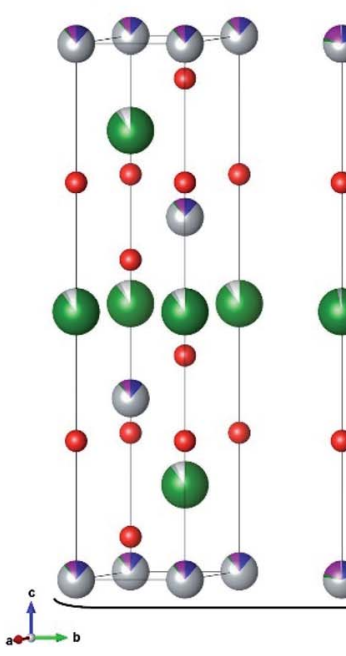

(b) NMC-622

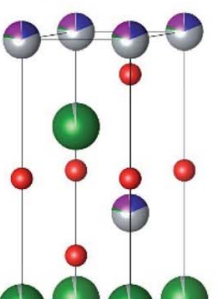

(c) NMC-433 ord.

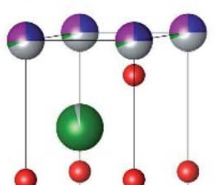

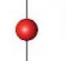
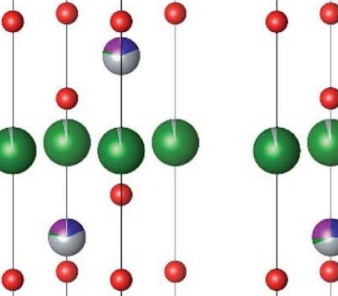

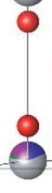
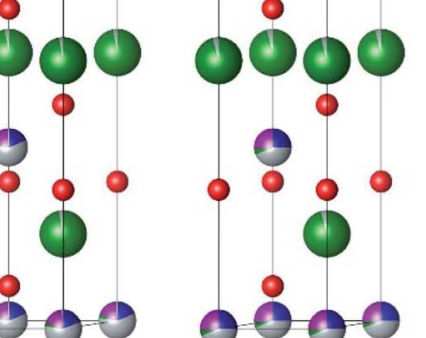

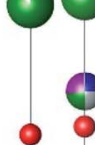

(d) NMC-433 Dis.

(e) $\mathrm{Li}_{2} \mathrm{MnO}_{3}$
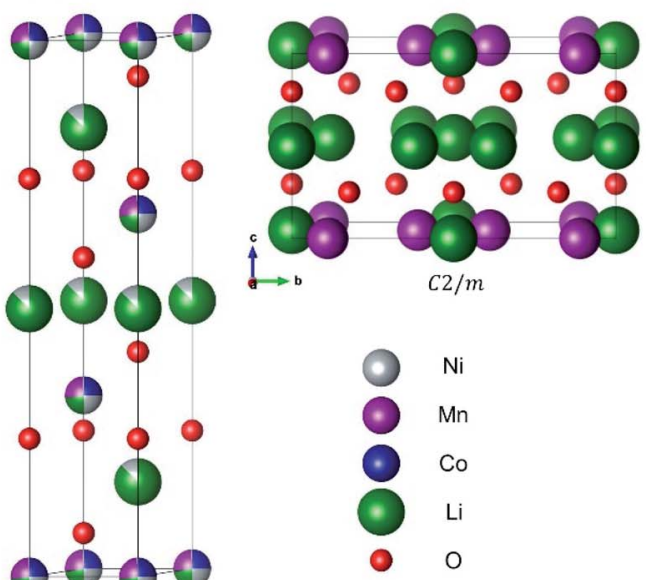

Fig. 7 Crystal structures of all major phases identified from NPD; the ordered $R \overline{3} m$ phase for (a) NMC-811, (b) NMC-622 and (c) NMC-433; (d) the disordered $R 3 \mathrm{~m}$ phase for NMC-433 and (e) the C2/m phase for NMC-433. 
instigating phase separation or cation mixing as $\mathrm{Co}^{3+}$ is known to nucleate and stabilise the $R \overline{3} m$ phase, and alleviate the magnetic frustration responsible for $\mathrm{Ni}^{2+}$ formation. ${ }^{37,38}$ Increased cation mixing has also been directly observed from combinatorial experiments when $\mathrm{Ni}$ is replaced for $\mathrm{Mn} .{ }^{39}$ Thus, it is likely that increasing Mn may both aggravate cation mixing, and encourage the formation of the $C 2 / m$ phase, if sufficient $\mathrm{Li}$ is available during heat treatment.

\section{Local lithium diffusion $(\mu \mathrm{SR})$}

Since the structures of the NMC materials differed significantly, it is important to establish the effect of these changes on lithium diffusion. Previously, $R \overline{3} m$ structures have been predicted to exhibit two intraplanar diffusion pathways through the $\mathrm{LiO}_{6}$ slab; the Oxygen Dumbbell Hop (ODH) and the Tetrahedral Site Hop (TSH). ${ }^{40}$ Previous investigations on isostructural materials have found the TSH mechanism to occur on a similar timescale $\left(\approx 10^{-10} \mathrm{~cm}^{2} \mathrm{~s}^{-1}\right)$, but provides a lower activation energy $\left(E_{\mathrm{a}}\right)$ diffusion pathway $\left(E_{\mathrm{a}}^{\mathrm{TSH}} \approx E_{\mathrm{a}}^{\mathrm{ODH}} / 4\right) \cdot{ }^{26}$ However, the TSH mechanism is only available where $[\mathrm{Li}]<1$ (due to the requirement for a $\mathrm{Li}$ divacancy). In comparison, the $C 2 / \mathrm{m}$ structure has previously been reported to exhibit additional interplanar diffusion pathways between the $\mathrm{Li}$ and $\mathrm{MO}_{6}$ slabs, which may be expected to provide enhanced Li ion conductivity. However, density functional theory (DFT) studies suggest that the average $E_{\mathrm{a}}$ of Li diffusion lies between 510 and $840 \mathrm{meV}$ in $C 2 / m \mathrm{LiMn}_{2} \mathrm{O}_{3}$, similar to values estimated by DFT for the ODH mechanism $(\sim 800 \mathrm{meV}){ }^{41}$

To understand the impact of nickel concentration and crystal structure on the local lithium diffusion mechanics, muon spin relaxation ( $\mu \mathrm{SR}$ ) experiments were performed on all three samples of NMC. Briefly, the powders were loaded into a titanium sample holder and exposed to a spin-polarized beam of muons in a vacuum using the EMU instrument at the STFC ISIS Neutron and Muon Facility, Harwell, UK. Muon decay asymmetry data were recorded at $300 \mathrm{~K}$ using a transverse magnetic field of $20 \mathrm{G}$ to normalise the initial decay asymmetry arising from the sample geometry. Data were then recorded between $160 \mathrm{~K}$ and $450 \mathrm{~K}$, applying three longitudinal fields of 0 , 5 and $10 \mathrm{G}$ at each temperature to decouple the muon spin relaxation from any nuclear magnetic contributions from $\mathrm{Ni}$, Mn or Co (Fig. 8a). The data from the three fields at each temperature were fit simultaneously to a modified KuboToyabe relaxation model to describe the dynamic diffusion processes multiplied by a Gaussian relaxation function to account for temperature independent fluctuations in $\mathrm{Li}^{+}$diffusion, with a constant background component (eqn (1)).

$$
\begin{array}{r}
A_{0} P_{\mathrm{LF}}(t)=A_{\mathrm{F}} \exp \left(-\lambda_{\mathrm{F}} t\right)+A_{\mathrm{KT}} \exp \left(-\lambda_{\mathrm{KT}} t\right) \times \\
G^{\mathrm{DGKT}}\left(\Delta, \nu, t, H_{\mathrm{LF}}\right)+A_{\mathrm{BG}}
\end{array}
$$

Two key parameters were extracted from the fits; (i) the field distribution width $(\Delta)$ which is a measure of the magnetic field distribution that the muon experiences at the implantation site and, (ii) the fluctuation rate $(\nu)$ which is a measure of the rate of muon decay perturbation from $\mathrm{Li}^{+}$diffusion, where $\nu \propto D_{\mathrm{Li}}$. Fig. $8 \mathrm{~b}$ shows the extracted values for $\Delta$ for the three NMC samples. It is observed that as temperature increases there is a corresponding decrease in the field distribution width due to $\mathrm{Li}^{+}$diffusion becoming more rapid and leading to a motional narrowing effect similar to that seen in previous investigations. ${ }^{26,42}$ As [Ni] increases (and thus, $[\mathrm{Mn}]$ and [Co] decreases) there is a consistent decrease in $\Delta$ due to the significantly smaller nuclear moment present in $\mathrm{Ni}$, when compared to $\mathrm{Mn}$ or Co.

Fig. 9a shows the extracted values of $\nu$ versus temperature where a steady increase was observed, indicating the thermal activation of $\mathrm{Li}$ diffusion. The data was used to estimate the average $D_{\mathrm{Li}}$ of each sample employing eqn (2); $N_{i}$ is the number of accessible $\mathrm{Li}^{+}$sites in the $i^{\text {th }}$ path, $Z_{\nu},{ }_{i}$ is the vacancy fraction
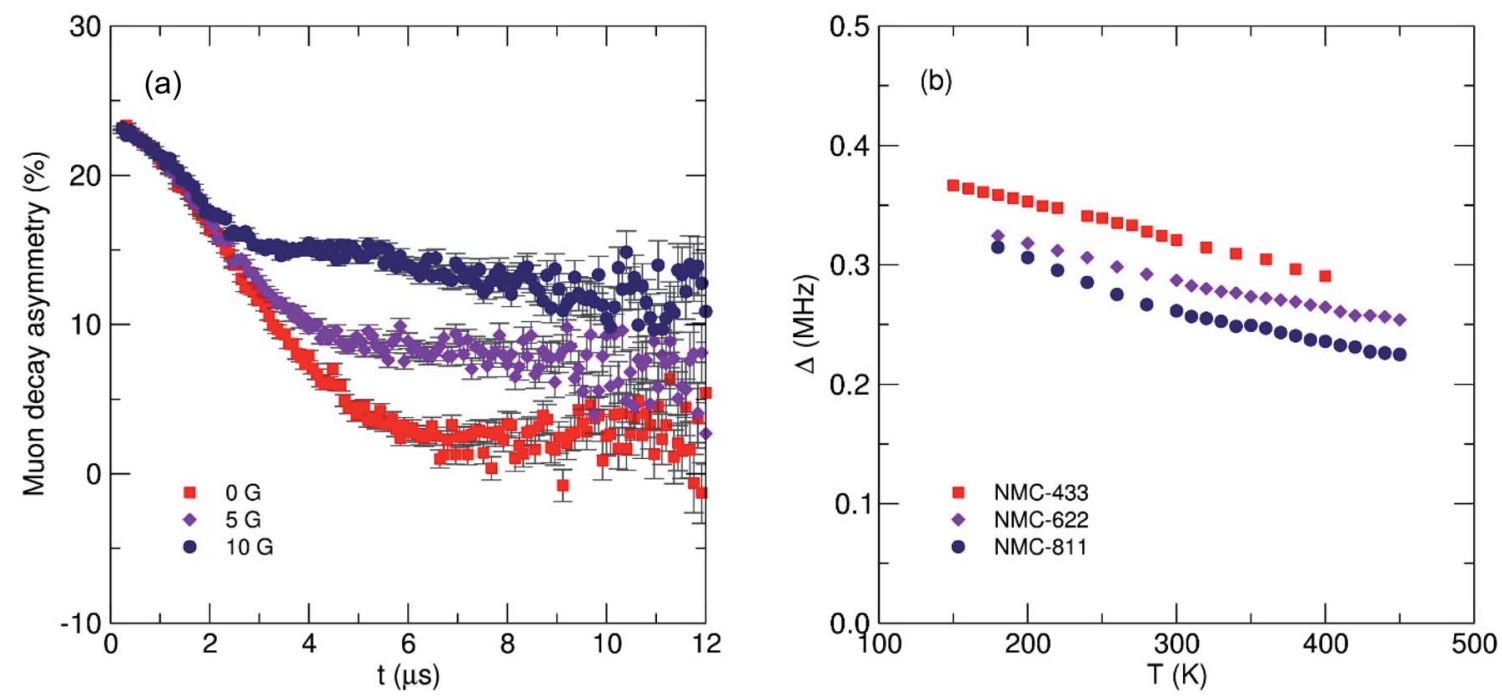

Fig. 8 (a) Fluctuation rate of muon decay $(\nu)$ and (b) field distribution width $(\Delta)$ observed from $\mu$ SR for three NMC compositions with increasing nickel content. The error for each $\Delta$ value is $<0.5 \%$. 

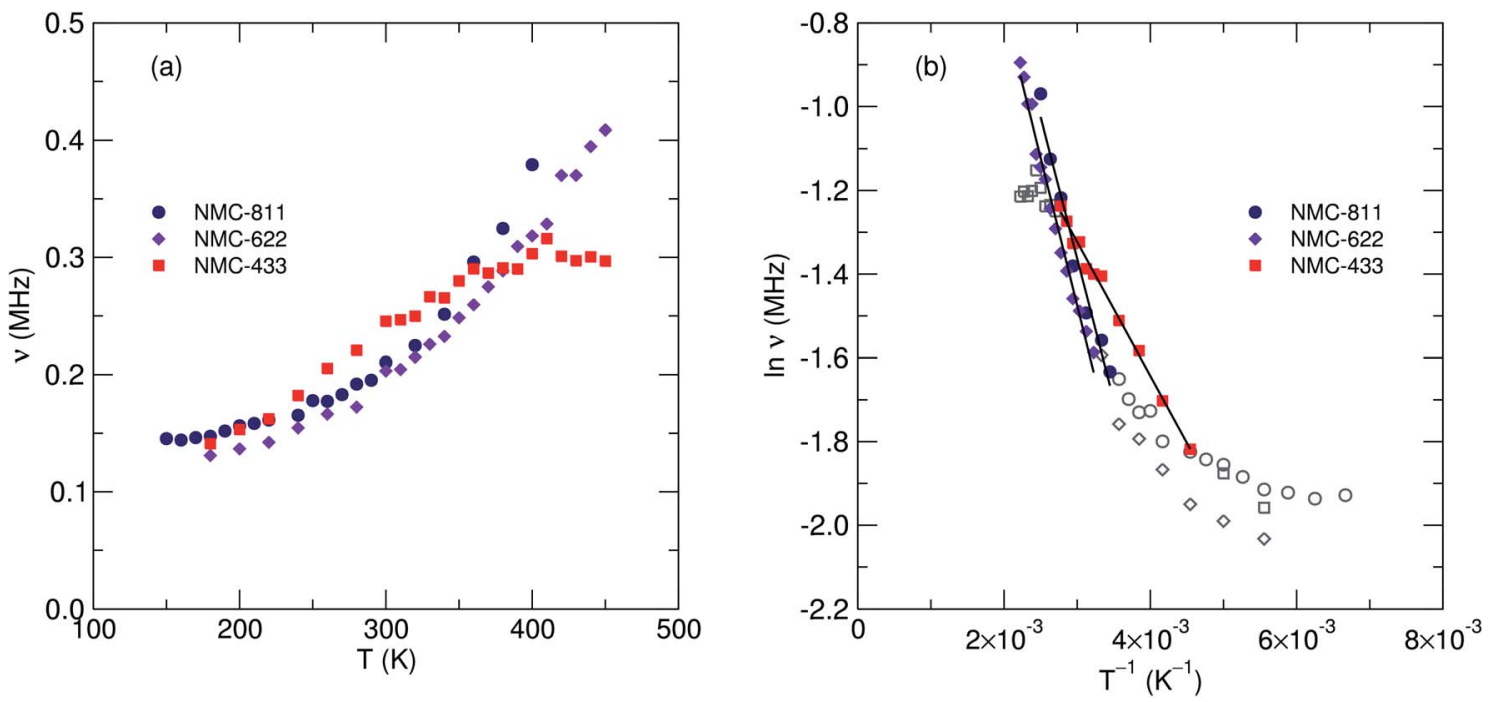

Fig. 9 (a) Extracted values of fluctuation rate $(\nu)$ versus measurement temperature. (b) Arrhenius plot of the fluctuation rate versus temperature for the three samples of NMC with increasing Ni content. Solid lines show the linear regression over the thermally activated regions for each sample. The thermally active range is shown in filled icons with their respective fits. The error for each data point is $<0.5 \%$.

of the destination sites, $s_{i}$ is the hopping distance between $\mathrm{Li}^{+}$ sites and $\nu$ is the fluctuation rate at each temperature. ${ }^{43}$ Structural values were extracted from the NPD refinements, and the calculation for NMC-433 included a weighted average of the three observed phases.

$$
D_{\mathrm{Li}}=\sum_{i=1}^{n} \frac{1}{N_{i}} Z_{\nu, i} S_{i}^{2} \nu
$$

Values of $D_{\mathrm{Li}}$ at $300 \mathrm{~K}$ for the two samples exhibiting only the $R \overline{3} \mathrm{~m}$ structure were determined to be $2.90 \times 10^{-11} \mathrm{~cm}^{2} \mathrm{~s}^{-1}$ for NMC-811 and $4.36 \times 10^{-11} \mathrm{~cm}^{2} \mathrm{~s}^{-1}$ for NMC-622. Statistical significance was confirmed by calculated errors of $\pm 1.75 \times$ $10^{-28}$ (NMC-811) $\pm 2.65 \times 10^{-28}$ (NMC-622) and $\pm 1.92 \times 10^{-20}$ (NMC-433). Using the Arrhenius relationship over the thermally activated region of each sample (Fig. 9b), $E_{\mathrm{a}}$ of muon hopping were found to be $58 \mathrm{meV}$ for NMC-811, $61 \mathrm{meV}$ for NMC-622 and $28 \mathrm{meV}$ for NMC-433. Compared to NMC-622, it is possible that the marginally slower but more facile diffusion of NMC-811 (indicated by both lower $D_{\mathrm{Li}}$ and $E_{\mathrm{a}}$ ) may be attributed to the

Table 2 Values of $D_{\mathrm{Li}}$ and $E_{\mathrm{a}}$ for the NMC-811, NMC-622 and NMC433 samples determined by muon spin relaxation. Values are also given for the $\mathrm{LiMn}_{2} \mathrm{O}_{3}$ and the isostructural $\mathrm{LiCoO}_{2}$ for comparison

\begin{tabular}{lll}
\hline Sample & $D_{\mathrm{Li}}\left(\mathrm{cm}^{2} \mathrm{~s}^{-1}\right)$ & $E_{\mathrm{a}}(\mathrm{meV})$ \\
\hline $\mathrm{NMC}-811$ & $2.9 \times 10^{-11}$ & $58.3 \pm 4.5$ \\
$\mathrm{NMC}-622$ & $4.4 \times 10^{-11}$ & $60.9 \pm 2.2$ \\
$\mathrm{NMC}-433$ & $3.4 \times 10^{-11}$ & $27.6 \pm 0.8$ \\
$\mathrm{LiMn}_{2} \mathrm{O}_{3}$ (ref. 51) & $4.7 \times 10^{-11}$ & 156 \\
$\mathrm{Li}_{0.73} \mathrm{CoO}_{2}$ (ref. 24) & $7.0 \times 10^{-10}$ & - \\
$\mathrm{Li}_{0.53} \mathrm{CoO}_{2}$ (ref. 24) & $2.5 \times 10^{-10}$ & - \\
$\mathrm{LiNi}_{\frac{1}{3}} \mathrm{Mn}_{\frac{1}{3}} \mathrm{CO}_{\frac{1}{3}} \mathrm{O}_{2}$ (ref. 52) & $3.5 \times 10^{-12}$ & $\approx 100$ \\
$\mathrm{Li}_{0.87} \mathrm{Ni}_{0.77} \mathrm{Co}_{0.14} \mathrm{Al}_{0.09} \mathrm{O}_{2}$ (ref. 26) & $3.0 \times 10^{-11}$ & $90 \pm 13$ \\
$\mathrm{Li}_{0.71} \mathrm{Ni}_{0.77} \mathrm{Co}_{0.14} \mathrm{Al}_{0.09} \mathrm{O}_{2}$ (ref. 26) & $1.0 \times 10^{-11}$ & $65 \pm 6$
\end{tabular}

$\mathrm{Li}$ vacancies. Lower $\left[\mathrm{Li}_{3 \mathrm{~b}}\right]$ causes less electrostatic repulsion between Li aiding diffusion (lowering $E_{\mathrm{a}}$ ), but provides less diffusion events for the muon decay to sample (lowering $\nu$ ). The lowering of $E_{\mathrm{a}}$ with decreasing $\left[\mathrm{Li}_{3 \mathrm{~b}}\right]$ has been previously predicted in the parent $\mathrm{LiCoO}_{2}$ by computational means, and observed in isostructural materials by $\mu \mathrm{SR}$ (Table 2). However, this does not preclude the possibility of the observed differences being solely or partly due to changes in transition metal stoichiometry, and the values of $E_{\mathrm{a}}$ for NMC-811 and NMC-622 lie within experimental error.

In comparison, while the estimated $D_{\mathrm{Li}}$ for NMC-433 was found to be $3.35 \times 10^{-11} \mathrm{~cm}^{2} \mathrm{~s}^{-1}$ the estimated value of $E_{\mathrm{a}}$ was $28 \mathrm{meV}$, significantly lower than that for NMC-811 or NMC-622. Although the structure of NMC-433 is too complex to be certain of the origin of the decrease in $E_{\mathrm{a}}$, it is unlikely to be due to the presence of $\mathrm{Li}_{2} \mathrm{MnO}_{3}$ as it was present $<10 \mathrm{~mol} \%$ of the total sample and has previously shown a larger $E_{\mathrm{a}}$ versus $R \overline{3} \mathrm{~m}$ structured materials (Table 2). Thus, it is likely that this marked decrease in $E_{\mathrm{a}}$ is either due to (i) the elevated concentration of $\mathrm{Mn}$ and/or Co or (ii) a contribution from the heavily disordered $R \overline{3} m$ phase.

\section{Conclusions}

Intimate studies of the three NMC samples (made using identical heat treatments) have provided direct evidence for stoichiometry driven phase formation. Neutron powder diffraction studies on 'Ni rich' NMC-811 has shown that while a single $R \overline{3} m$ phase can be obtained; Li incorporation is more challenging (under similar synthetic conditions) compared to the lower $\mathrm{Ni}$ content NMC-622. However, lowering the Ni content further in NMC-433 leads to a dramatic structural disruption and the evolution of three phases; an ordered $R \overline{3} m$ phase, a disordered $R \overline{3} m$ phase with a high degree of $\mathrm{Li}_{3 \mathrm{a}}{ }^{+} / \mathrm{Ni}_{3 \mathrm{~b}}{ }^{2+}$ mixing, and a $\mathrm{Li}$ rich $C 2 / m$ phase. In this case, the authors suggest that this is 
more likely due to the presence of elevated [Mn], rather than diminished [Ni] and the available excess of Li during solid-state lithiation. Differences in the local diffusion mechanics were also identified, with well-ordered NMC-622 showing the highest diffusion coefficient of the three materials. Interestingly, mixed phase NMC-433 showed a significantly lower activation energy than NMC-811 or NMC-622 despite the large amount of structural disorder.

In closing, it is of paramount importance to interpret results given from PXRD responsibly. Although no significant cation mixing was detected with PXRD, this is not proof of its absence; a vastly different story was told by using NPD data that showed not only cation mixing, but multiple crystalline phases. It is also important that $I_{(003)} / I_{(104)}$ is not accurate in solely determining the $\mathrm{Li}_{3 \mathrm{a}}{ }^{+} / \mathrm{Ni}_{3 \mathrm{~b}}{ }^{2+}$ mixing in NMC materials, as vacancies and closely related crystal structures may also have a large impact on the results.

\section{Experimental}

\section{Synthesis of lithium nickel manganese cobalt oxide (NMC)}

To prepare the nanoparticulate NMC precursors a continuous hydrothermal flow synthesis (CHFS) process was used, which has been described elsewhere. ${ }^{\mathbf{2 6 , 4 4}}$ To summarise the process, three diaphragm pumps (Primeroyal K, Milton Roy, Pont-SaintPierre, France) were used to supply feeds of deionized water $\left(P_{\mathrm{SW}}\right)$, an aqueous solution of the metal salts $\left(P_{\mathrm{M}}\right)$, and a $1 \mathrm{M}$ $\mathrm{KOH}$ solution $\left(P_{\text {base }}\right)$ at flow rates of 80,40 and $40 \mathrm{~mL} \mathrm{~min}{ }^{-1}$, respectively. All chemicals were obtained from Sigma-Aldrich, Dorset, UK.

The NMC compositions were prepared by mixing the appropriate amount of metal nitrate salts $\left[\mathrm{Ni}\left(\mathrm{NO}_{3}\right)_{2} \cdot 6 \mathrm{H}_{2} \mathrm{O}\right.$, $\mathrm{Mn}\left(\mathrm{NO}_{3}\right) \cdot x \mathrm{H}_{2} \mathrm{O}$ and $\left.\mathrm{Co}\left(\mathrm{NO}_{3}\right)_{3} \cdot 6 \mathrm{H}_{2} \mathrm{O}\right]$, summarised in Table S1. $\dagger$ The DI water feed from pump $P_{\mathrm{sw}}$ was heated in flow to $450{ }^{\circ} \mathrm{C}$ using a $7 \mathrm{~kW}$ custom-built in-line electrical heater. Precursor feeds from pumps $P_{\mathrm{M}}$ and $P_{\text {base }}$ were separately mixed in a Tpiece in flow (at room temperature) prior to mixing in flow with the combined superheated water feed in the patented (WO2011148121A1) confined jet mixer (CJM). ${ }^{45}$ In all cases, the total concentration of metals, $P_{\mathrm{M}}$ was fixed at $0.5 \mathrm{M}$ and the concentration of base, $P_{\text {base }}$ was fixed at $1 \mathrm{M}$. Upon mixing of the feeds in the CHFS process, nanoparticles were formed, which were then cooled to $\sim 40{ }^{\circ} \mathrm{C}$ using a $1.5 \mathrm{~m}$ counter-current pipein-pipe heat exchanger, before being passed through a backpressure regulator (BPR) valve at the CHFS outlet. The aqueous nanoparticle slurry exiting the BPR was collected and cleaned by repeated centrifugation and washing with deionized water until the conductivity of the supernatant was consistently below $50 \mu \mathrm{S}$, as measured by a conductivity probe (Hanna Instruments, model HI98311, Leighton Buzzard, UK). The concentrated slurry was then freeze-dried (Virtis Genesis 35XL) by gradually heating a sample from -60 to $25{ }^{\circ} \mathrm{C}$ (over $24 \mathrm{~h}$ ) in vacuo (<100 mTorr), which yielded free-flowing dark brown/ black powders in all cases.

The NMC precursor powders were then mixed with a $30 \%$ molar excess of $\mathrm{LiOH}$ in a Thinky ${ }^{\mathrm{TM}}$ mixer for $30 \mathrm{~min}$ at $1500 \mathrm{rpm}$ and heat treated in a box furnace at $800{ }^{\circ} \mathrm{C}$ for 5 hours in air (ramp rate $5{ }^{\circ} \mathrm{C} \min ^{-1}$ ). The resulting black powders were characterised and tested with no further modification.

\section{Structural characterisation (PXRD and NPD)}

Powder X-ray diffraction (XRD) patterns were collected using a STOE Stadi $\mathrm{P}$ diffractometer in transmission geometry (Mo$\mathrm{K} \alpha_{1}$ radiation, $\lambda=0.70932 \AA$ ), equipped with a germanium (111) monochromator and a DECTRIS Mythen $1 \mathrm{k}$ silicon strip detector (DECTRIS, Baden, Switzerland). An Yttria $\left(\mathrm{Y}_{2} \mathrm{O}_{3}\right)$ standard was used to estimate instrumental peak broadening. Datasets were collected over the $2 \theta$ range of 2 to $40^{\circ}$ with a step size of $0.5^{\circ}$ and a count time of $5 \mathrm{~s}$ per step.

Time-of-flight (TOF) neutron powder diffraction (NPD) was carried out on the iMATERIA diffractometer at J-PARC. ${ }^{46}$ The each as-synthesized powder sample $(\sim 2.5 \mathrm{~g})$ was placed into vanadium cell, which was installed to iMATERIA. In this study, a wide $d$-spacing $(0.11<d<5.29 \AA)$ and a high resolution $(\Delta d /$ $d=0.16 \%$ ) were used for the TOF NPD measurements. The sample environment of iMATERIA was evacuated to prevent incoherent scattering of water vapor (H atoms). All experiments were measured for $4 \mathrm{~h}$ at room temperature. The beam power of the J-PARC for NPD measurements was $500 \mathrm{~kW}$. The data was analysed by Rietveld refinement using the Z-Rietveld software package (ver. 1.0.2). ${ }^{47,48}$ In the case of both NMC-811 and NMC622 , the Rietveld refinements were demonstrated between $d=$ 0.35 and $4.95 \AA$, whereas that of NMC-433 was done the region between $d=0.70$ and $5.08 \AA$.

\section{Scanning electron microscopy (SEM)}

Scanning electron microscopy (SEM) was performed using a JEOL JSM-6700F microscope. To minimise charging samples were deposited on copper foil tape, mounted on aluminium stubs, after dispersion in methanol (99.9\%, Sigma Aldrich, Dorset, UK) and ultrasonication in a XUBA3 Ultrasonic Bath (Grant Instruments, Cambridge, UK) for 5 minutes. Image analysis was carried out using ImageJ software.

\section{Elemental analysis (ICP-MS)}

Inductively coupled plasma mass spectrometry (ICP-MS) was carried out by fully dissolving each sample in concentrated hydrochloric acid overnight by microwave digestion (CEM Discover SP). These solutions were then diluted with dilute hydrochloric acid prior to analysis by ICP-MS (Agilent 7500ce). Calibration curves were constructed with elemental standards and used to calculate the concentrations of $\mathrm{Ni}, \mathrm{Mn}$, Co and $\mathrm{Li}$ for each sample.

\section{Local diffusion analyses ( $\mu \mathrm{SR})$}

Muon spin relaxation experiments were performed at STFC ISIS Neutron and Muon Source, Harwell, UK. Approximately $3.0 \mathrm{~g}$ of powdered samples of NMC-811, NMC-622 or NMC-433 were packed into recessed titanium sample holders, covered with a titanium window and secured with a titanium bezel. The titanium holder provided a simple background signal from muons that are not implanted into the sample and any signal is 
easily subtracted from the data. The sample holder was placed into the muon spectrometer (EMU) and evacuated to $<1 \times 10^{-6}$ mbar. The instrument was cooled to a temperature of $150 \mathrm{~K}$ and instrument asymmetry was measured using a transverse magnetic field of $20 \mathrm{G}$. Measurements were taken every $10 \mathrm{~K}$ up to $450 \mathrm{~K}$, with longitudinal at fields of 0,5 and $10 \mathrm{G}$. Data collected at each temperature for the three applied magnetic fields were fit simultaneously using the WiMDA software. ${ }^{49}$

\section{Conflicts of interest}

There are no conflicts to declare.

\section{Acknowledgements}

Muon experiments at the ISIS Neutron and Muon Source were supported by a beamtime allocation RB1810750 from the Science and Technology Facilities Council. ${ }^{50}$ Neutron experiments at the J-PARC Materials \& Life Science Division were supported by a beamtime allocation 2018B0196. JAD and TEA would like to thank the EPSRC grant EP/R023662/1, Joint University Industry Consortium for Energy (Materials) and Devices Hub (JUICED), for support.

\section{References}

1 Y. Xia, J. Zheng, C. Wang and M. Gu, Nano Energy, 2018, 49, 434-452.

2 M. D. Radin, S. Hy, M. Sina, C. Fang, H. Liu, J. Vinckeviciute, M. Zhang, M. S. Whittingham, Y. S. Meng and A. Van der Ven, Adv. Energy Mater., 2017, 7, 1-33.

3 K. Jalkanen, J. Karppinen, L. Skogström, T. Laurila, M. Nisula and K. Vuorilehto, Appl. Energy, 2015, 154, 160172.

4 C. Delmas, M. Ménétrier, L. Croguennec, I. Saadoune, A. Rougier, C. Pouillerie, G. Prado, M. Grüne and L. Fournès, Electrochim. Acta, 1999, 45, 243-253.

5 D. Andre, S.-J. Kim, P. Lamp, S. F. Lux, F. Maglia, O. Paschos and B. Stiaszny, J. Mater. Chem. A, 2015, 3, 6709-6732.

6 S. Zhang, J. Ma, Z. Hu, G. Cui and L. Chen, Chem. Mater., 2019, 31, 6033-6065.

7 Y. Shao-Horn, L. Croguennec, C. Delmas, E. C. Nelson and M. A. O'Keefe, Nat. Mater., 2003, 2, 464-467.

8 R. Weber, H. Li, W. Chen, C.-Y. Kim, K. Plucknett and J. R. Dahn, J. Electrochem. Soc., 2020, 167, 100501.

9 S.-M. Bak, E. Hu, Y. Zhou, X. Yu, S. D. Senanayake, S.-J. Cho, K.-B. Kim, K. Y. Chung, X.-Q. Yang and K.-W. Nam, ACS Appl. Mater. Interfaces, 2014, 6, 22594-22601.

10 H. Ronduda, M. Zybert, A. Szczęsna-Chrzan, T. Trzeciak, A. Ostrowski, D. Szymański, W. Wieczorek, W. RarógPilecka and M. Marcinek, Nanomaterials, 2020, 10, 2018.

11 H. Dong and G. M. Koenig, CrystEngComm, 2020, 22, 15141530.

12 D. Ren, Y. Shen, Y. Yang, L. Shen, B. D. A. Levin, Y. Yu, D. A. Muller and H. D. Abruña, ACS Appl. Mater. Interfaces, 2017, 9, 35811-35819.
13 Y. Duan, L. Yang, M.-J. Zhang, Z. Chen, J. Bai, K. Amine, F. Pan and F. Wang, J. Mater. Chem. A, 2019, 7, 513-519.

14 V. Pimenta, M. Sathiya, D. Batuk, A. M. Abakumov, D. Giaume, S. Cassaignon, D. Larcher and J.-M. Tarascon, Chem. Mater., 2017, 29, 9923-9936.

15 J. Zheng, Y. Ye, T. Liu, Y. Xiao, C. Wang, F. Wang and F. Pan, Acc. Chem. Res., 2019, 52(8), 2201-2209.

16 R. Wang, G. Qian, T. Liu, M. Li, J. Liu, B. Zhang, W. Zhu, S. Li, W. Zhao, W. Yang, X. Ma, Z. Fu, Y. Liu, J. Yang, L. Jin, Y. Xiao and F. Pan, Nano Energy, 2019, 62, 709-717.

17 J. H. Hubbell and S. M. Seltzer, NIST: X-Ray Mass Attenuation Coefficients.

18 K. Märker, C. Xu and C. P. Grey, J. Am. Chem. Soc., 2020, 142, 17447-17456.

19 V. Charbonneau, A. Lasia and G. Brisard, J. Electroanal. Chem., 2020, 875, 113944.

20 C.-H. Chen, F. Brosa Planella, K. O'Regan, D. Gastol, W. D. Widanage and E. Kendrick, J. Electrochem. Soc., 2020, 167, 080534.

21 O. Capron, R. Gopalakrishnan, J. Jaguemont, P. Van Den Bossche, N. Omar and J. Van Mierlo, Materials, 2018, 11(2), 176.

22 M. Månsson and J. Sugiyama, Phys. Scr., 2013, 88, 068509.

23 K. Mukai, J. Sugiyama, Y. Ikedo, H. Nozaki, K. Shimomura, K. Nishiyama, K. Ariyoshi and T. Ohzuku, J. Power Sources, 2007, 174, 711-715.

24 J. Sugiyama, K. Mukai, Y. Ikedo, H. Nozaki, M. Månsson and I. Watanabe, Phys. Rev. Lett., 2009, 103, 147601.

25 J. Sugiyama, Y. Ikedo, K. Mukai, H. Nozaki, M. Månsson, O. Ofer, M. Harada, K. Kamazawa, Y. Miyake, J. H. Brewer, E. J. Ansaldo, K. H. Chow, I. Watanabe and T. Ohzuku, Phys. Rev. B: Condens. Matter Mater. Phys., 2010, 82, 224412.

26 T. E. Ashton, P. J. Baker, D. Bauer, A. R. Groves, C. SoteloVazquez, T. Kamiyama, T. Matsukawa, K. M. Kojima and J. A. Darr, J. Mater. Chem. A, 2020, 8, 11545-11552.

27 P. Rozier and J. M. Tarascon, J. Electrochem. Soc., 2015, 162, A2490-A2499.

28 S. Kim, M. Aykol, V. I. Hegde, Z. Lu, S. Kirklin, J. R. Croy, M. M. Thackeray and C. Wolverton, Energy Environ. Sci., 2017, 10, 2201-2211.

29 M. M. Thackeray, S.-H. Kang, C. S. Johnson, J. T. Vaughey, R. Benedek and S. A. Hackney, J. Mater. Chem., 2007, 17, 3112.

30 A. K. Shukla, Q. M. Ramasse, C. Ophus, H. Duncan, F. Hage and G. Chen, Nat. Commun., 2015, 6, 8711.

31 A. K. Shukla, Q. M. Ramasse, C. Ophus, D. M. Kepaptsoglou, F. S. Hage, C. Gammer, C. Bowling, P. A. H. Gallegos and S. Venkatachalam, Energy Environ. Sci., 2018, 11, 830-840.

32 M. M. Thackeray, S.-H. Kang, C. S. Johnson, J. T. Vaughey and S. A. Hackney, Electrochem. Commun., 2006, 8, 15311538.

33 A. Rougier, P. Gravereau and C. Delmas, J. Electrochem. Soc., 1996, 143, 1168.

34 X. Zhang, W. J. Jiang, A. Mauger, L. Qi, F. Gendron and C. M. Julien, J. Power Sources, 2010, 195, 1292-1301. 
35 J. Zheng, G. Teng, C. Xin, Z. Zhuo, J. Liu, Q. Li, Z. Hu, M. Xu, S. Yan, W. Yang and F. Pan, J. Phys. Chem. Lett., 2017, 8, 5537-5542.

36 E. McCalla, C. M. Lowartz, C. R. Brown and J. R. Dahn, Chem. Mater., 2013, 25, 912-918.

37 A. Ueda and T. Ohzuku, J. Electrochem. Soc., 1994, 141, 20102014.

38 B. Xiao, T. Rojo and X. Li, ChemSusChem, 2019, 12, 133-144.

39 L. Yin, Z. Li, G. S. Mattei, J. Zheng, W. Zhao, F. Omenya, C. Fang, W. Li, J. Li, Q. Xie, E. M. Erickson, J.-G. Zhang, M. S. Whittingham, Y. S. Meng, A. Manthiram and P. G. Khalifah, Chem. Mater., 2020, 32, 1002-1010.

40 A. Van der Ven, Electrochem. Solid-State Lett., 1999, 3, 301.

41 R. Xiao, H. Li and L. Chen, Chem. Mater., 2012, 24, 42424251.

42 T. E. Ashton, J. V. Laveda, D. A. MacLaren, P. J. Baker, A. Porch, M. O. Jones and S. A. Corr, J. Mater. Chem. A, 2014, 2, 6238-6245.

43 R. Borg and G. Dienes, An introduction to solid state diffusion, Elsevier, Burlington, MA, 1st edn, 2012.

44 J. A. Darr, J. Zhang, N. M. Makwana and X. Weng, Chem. Rev., 2017, 117, 11125-11238.
45 J. Darr, C. J. Tighe and R. Gruar, WO2011148121A1, p. 2011. 46 T. Ishigaki, A. Hoshikawa, M. Yonemura, T. Morishima, T. Kamiyama, R. Oishi, K. Aizawa, T. Sakuma, Y. Tomota, M. Arai, M. Hayashi, K. Ebata, Y. Takano, K. Komatsuzaki, H. Asano, Y. Takano and T. Kasao, Nucl. Instrum. Methods Phys. Res., Sect. A, 2009, 600, 189-191.

47 R. Oishi, M. Yonemura, Y. Nishimaki, S. Torii, A. Hoshikawa, T. Ishigaki, T. Morishima, K. Mori and T. Kamiyama, Nuclear Instruments and Methods in Physics Research Section A: Accelerators, Spectrometers, Detectors and Associated Equipment, 2009, 600, 94-96.

48 R. Oishi-Tomiyasu, M. Yonemura, T. Morishima, A. Hoshikawa, S. Torii, T. Ishigaki and T. Kamiyama, J. Appl. Crystallogr., 2012, 45, 299-308.

49 F. L. Pratt, Phys. B, 2000, 289-290, 710-714.

50 T. E. Ashton, J. A. Darr and P. J. Baker, STFC ISIS Neutron Muon Source, DOI: 10.5286/ISIS.E.RB1810750.

51 J. Sugiyama, H. Nozaki, K. Mukai, M. Harada, M. Månsson and A. Hillier, Solid State Ionics, 2014, 262, 901-903.

52 M. Månsson, H. Nozaki, J. M. Wikberg, K. Prša, Y. Sassa, M. Dahbi, K. Kamazawa, K. Sedlak, I. Watanabe and J. Sugiyama, J. Phys.: Conf. Ser., 2014, 551, 012037. 